\title{
Rupture of Fetal Vessels on Placental Surface ${ }^{\star}$
}

\author{
D. J. DESA \\ From Harkness Laboratory, Department of Pathology, Radcliffe Infirmary, Oxford
}

\begin{abstract}
deSa, D. J. (1971). Archives of Disease in Childhood, 46, 495. Rupture of fetal vessels on placental surface. Six placentae with subamniotic haematomata were studied and the lesions shown to be derived from ruptured varices of surface fetal veins. However, the changes in the vessel walls suggested that these fetal varices had been subjected to an increase of pressure for some time. Furthermore, the fetal veins of the affected placentae were lined by thick intimal cushions that were derived from organizing thrombi. Analysis of the clinical features of these pregnancies suggested an association of the vascular abnormalities with infants of low birthweight score, an opinion that was strengthened by an assessment of the fetal vessels in 100 placentae from normal pregnancies and 35 placentae from a 'fetus-at-risk' study.
\end{abstract}

Six placentae with readily visible subamniotic haematomata (Fig. 1) were studied over an 18month period (July 1969 to December 1970). This paper records the pathology of these lesions and of the underlying fetal surface vessels with which they seem to be associated.

\section{Materials and Methods}

The placentae were weighed and their volume estimated by a water displacement method. Serial slices, $1 \mathrm{~cm}$ thickness, were taken through the placenta after fixation in formol-saline, and numerous blocks were then taken from the entire placenta so as to include both the fetal and maternal surface and processed through to paraffin. Sections were stained routinely with haematoxylin and eosin (H. and E.), with Lendrum's Martius Scarlet Blue (MSB) for fibrin, and Alcian Blue $(p \mathrm{H}$ 2.2) counterstained by periodic acid-Schiff (AB/PAS) for mucopolysaccharides. The volume of the haematoma was estimated by a point-counting procedure (Dunnill, 1968). The clinical history and outcome of these pregnancies was collected and analysed. In view of the findings in these 6 placentae with subamniotic haematomas, it was felt necessary to study a wider range of control material.

Placental blocks from 100 normal pregnancies were available and these were re-examined using the staining procedures outlined above. In addition, the blocks from 35 placentae from a 'fetus-at-risk' study currently in progress in Oxford were also available, and were studied by the same histological procedures. Clinical details of these 'at-risk' pregnancies were then obtained after a histological assessment had been made.

Received 17 February 1971.

^Based on a paper presented to the Neonatal Society, London, 4 February 1971.

\section{Results}

Clinical features of subamniotic haematoma cases. In Table $I$ it can be seen that 4 infants had a low birthweight score (Gruenwald, 1969) and 4 of the mothers had raised blood pressure. There were 3 perinatal deaths, and the survivors had low Apgar scores and difficulty in establishing respiration. On attempting a comparison of the estimated blood lost in the haematoma and the outcome, no clear correlation could be seen whether or not the amount lost was considered

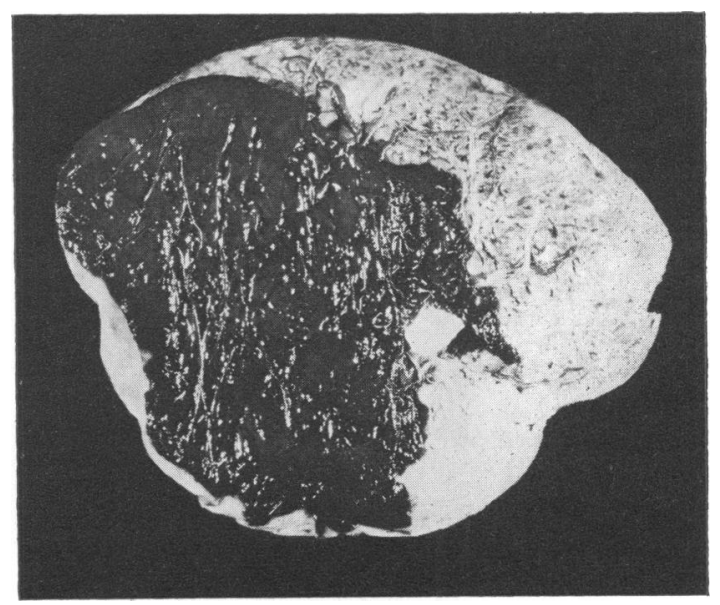

FIG. 1.-The fetal surface of the placenta (Case 2) showing the extensive subamniotic haematoma whose estimated volume was $30 \mathrm{ml}$. 
TABLE I

Summary of Clinical Features in Cases with Subamniotic Haematomata

\begin{tabular}{|c|c|c|c|c|c|c|}
\hline $\begin{array}{l}\text { Case } \\
\text { No. }\end{array}$ & $\begin{array}{l}\text { Gestation } \\
\quad(\mathbf{w k})\end{array}$ & $\begin{array}{l}\text { Birthweight (g) } \\
\text { (and Score) }\end{array}$ & $\begin{array}{c}\text { Maternal } \\
\text { Factors }\end{array}$ & $\begin{array}{l}\text { Estimated Blood } \\
\text { Loss (approx) }\end{array}$ & $\begin{array}{l}\text { Apgar Score } \\
\text { (at } 1 \mathrm{~min})\end{array}$ & $\begin{array}{l}\text { Outcome of } \\
\text { Pregnancy }\end{array}$ \\
\hline 1 & 34 & $1700(0)$ & PET* & $\begin{array}{c}20 \mathrm{ml} \\
(11.8 \mathrm{ml} / \mathrm{kg})\end{array}$ & 3 & $\begin{array}{l}\text { Neonatal death at } 4 \mathrm{hr} \text {; RDS; } \\
\text { haemorrhagic necrosis of } \\
\text { adrenals }\end{array}$ \\
\hline 2 & 36 & $1520(-2)$ & $\begin{array}{l}\text { Small-for-dates; falling } \\
\text { oestriols induced }\end{array}$ & $\begin{array}{c}30 \mathrm{ml} \\
(19 \cdot 7 \mathrm{ml} / \mathrm{kg})\end{array}$ & 4 & $\begin{array}{l}\text { Neonatal apnoea; eventual } \\
\text { recovery; alive and well }\end{array}$ \\
\hline 3 & 39 & $2390(-2)$ & Hypertension near term & $\begin{array}{c}15 \mathrm{ml} \\
(6.3 \mathrm{ml} / \mathrm{kg})\end{array}$ & 4 & Neonatal apnoea; alive and well \\
\hline 4 & 37 & $2200(-1)$ & PET & $\begin{array}{c}10 \mathrm{ml} \\
(4.5 \mathrm{ml} / \mathrm{kg})\end{array}$ & 5 & Neonatal apnoea; alive and well \\
\hline 5 & 38 & $2050(-2)$ & PET & $\begin{array}{c}10 \mathrm{ml} \\
(4.9 \mathrm{ml} / \mathrm{kg})\end{array}$ & 0 & Stillbirth (fresh) \\
\hline 6 & 39 & $3150(0)$ & $\begin{array}{l}\text { No antenatal care; } \\
\text { admitted in labour }\end{array}$ & $\begin{array}{l}20 \mathrm{ml} \\
(9.5 \mathrm{ml} / \mathrm{kg})\end{array}$ & 0 & Stillbirth (fresh) \\
\hline
\end{tabular}

$\star$ PET $=$ pre-eclamptic toxaemia.

in absolute terms or in relation to body weight. Haemoglobin levels in the infants were unfortunately not available. All the infants were delivered vaginally by the vertex. No information was available regarding the time elapsed after delivery of the infant and before clamping the cord.

Pathological findings in subamniotic haematoma placentae. In all the cases the subamniotic bleeding was a recent event and could be traced to ruptured varices of surface tributaries of the umbilical veins. The chorionic plate was intact (Fig. 2). Sections of the vessel wall near the point of rupture showed two main abnormalities: excess amounts of acid mucopolysaccharide separating the muscle bundles of the media and the presence of considerable amounts of material within the media that stained positively for fibrin with MSB (Fig. 3b).

The most interesting changes, however, were those seen in the fetal surface and truncal vessels underlying the haematoma. In all 6 cases the architecture of the surface veins was deranged by the presence of large intimal cushions of loose myxoid tissue on which surface thrombi were frequently seen (Fig. 4). Evidence of fibrin (Fig.

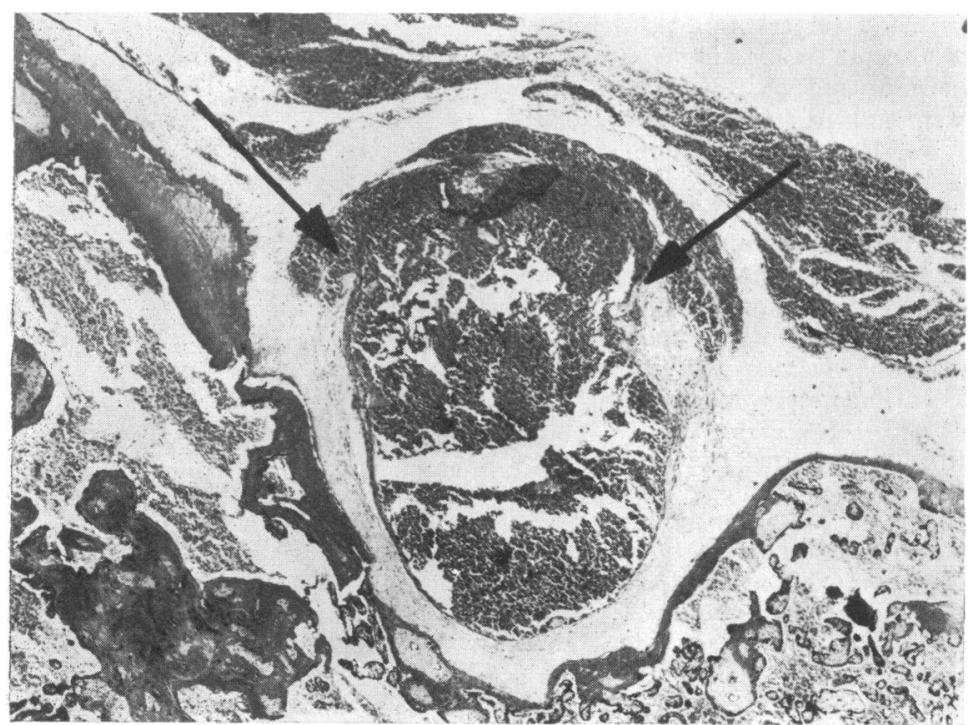

FIG. 2.-Ruptured varix in Case 1. Note the extensive area of rupture (between arrows) and the dissection of blood around the vein and into the subamniotic tissue. (H. and $E . \times 23$.) 


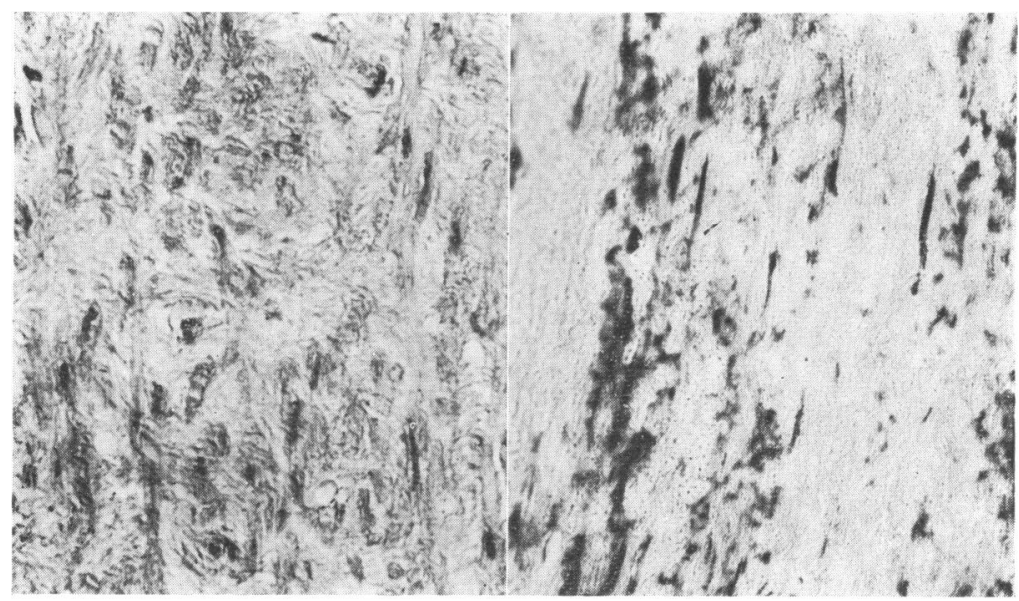

(a)

(b)

FIG. 3.-Sections of the varix wall near the point of rupture (Case 1). (a) Excessive amounts of pale acid mucopolysaccharide are responsible for the wide separation of muscle fibres. (Alcian Blue-periodic acid-Schiff $\times 280$ ).

(b) Infiltration of the vessel wall by fibrin (showing up as darker component). (MSB $\times 280)$.

5) within these large cushions pointed to their origin from organizing thrombi. These large cushions with their abundant acid mucopolysaccharides were not confined to the surface veins, but in all 6 cases abundant evidence of similar involvement of the truncal veins was also seen (Fig. 6). In 3 cases the truncal vessels showed the presence of organizing thrombi being incorporated into endothelial cushions (Fig. 7), and in 3 other cases thrombi could be seen lying free in these deeper vessels (Fig. 8). The arteries appeared unremarkable and the villous vessels appeared surprisingly unaffected.

The large cushions seen in these cases and their obvious derivation from organizing thrombi were considered to be the major feature of these cases. For the remainder of this paper, placentae with intimal cushions of a thickness greater than the

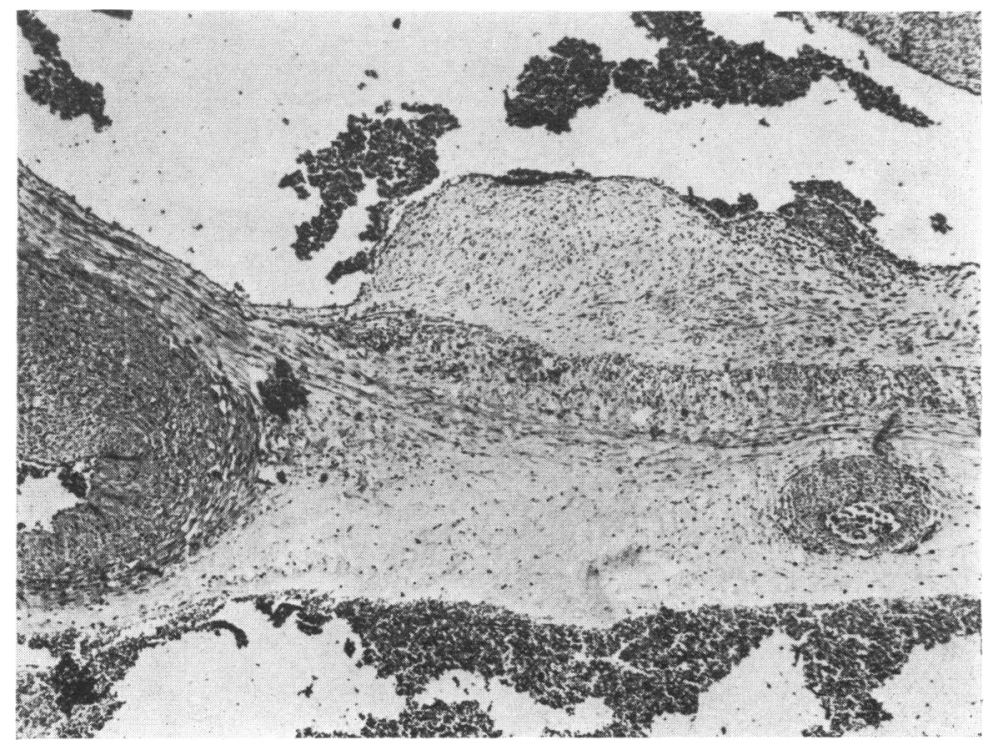

Fig. 4.-Major intimal cushion (Case 4) with organizing surface thrombus. Part of walls of surface branches of the umbilical arteries are also seen. (H. and $E . \times 36)$. 


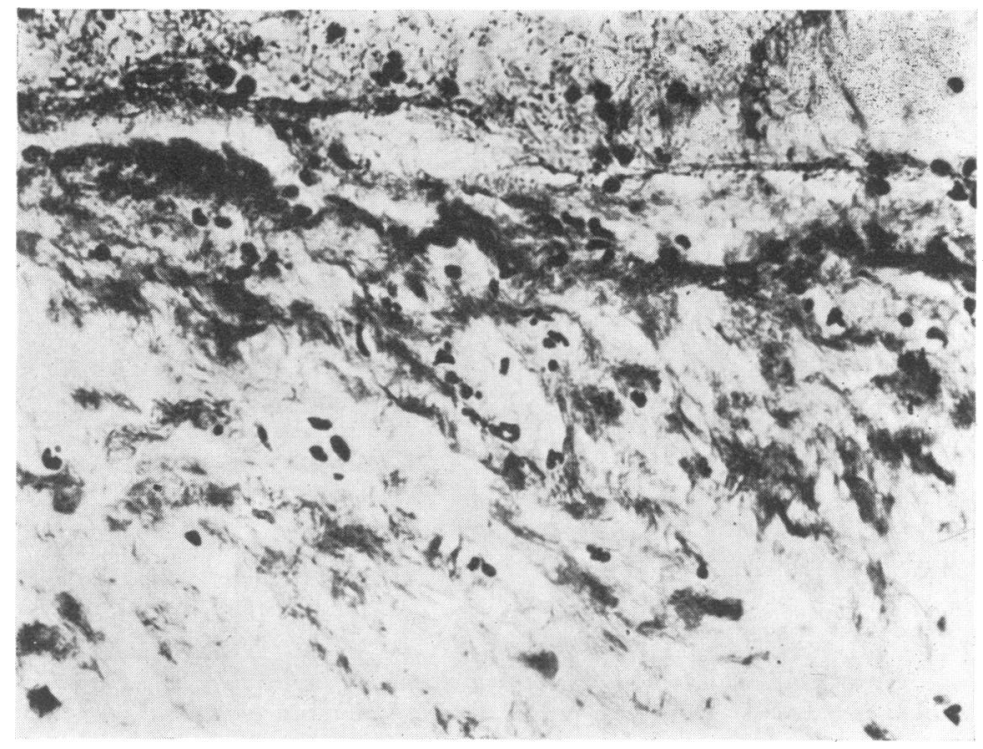

FIG. 5.-Fibrin strands in deeper layers of initimal cushion (Case 3). (MSB $\times 360$.)

remainder of the vessel wall, with abundant and frequent evidence of organizing thrombi in relation to them and with large areas of acid mucopolysaccharide in their stroma will be referred to as placentae showing the presence of major cushions. This is to distinguish them from the placentae to be described below. The summary of histological findings in the subamniotic haematoma cases is shown in Table II.

Findings in 'normal' and 'at-risk' cases. Two of the 100 'normal' placentae and 8 of the 35 'at-risk' placentae were seen to have major cushions. The other placentae all had varices with intimal

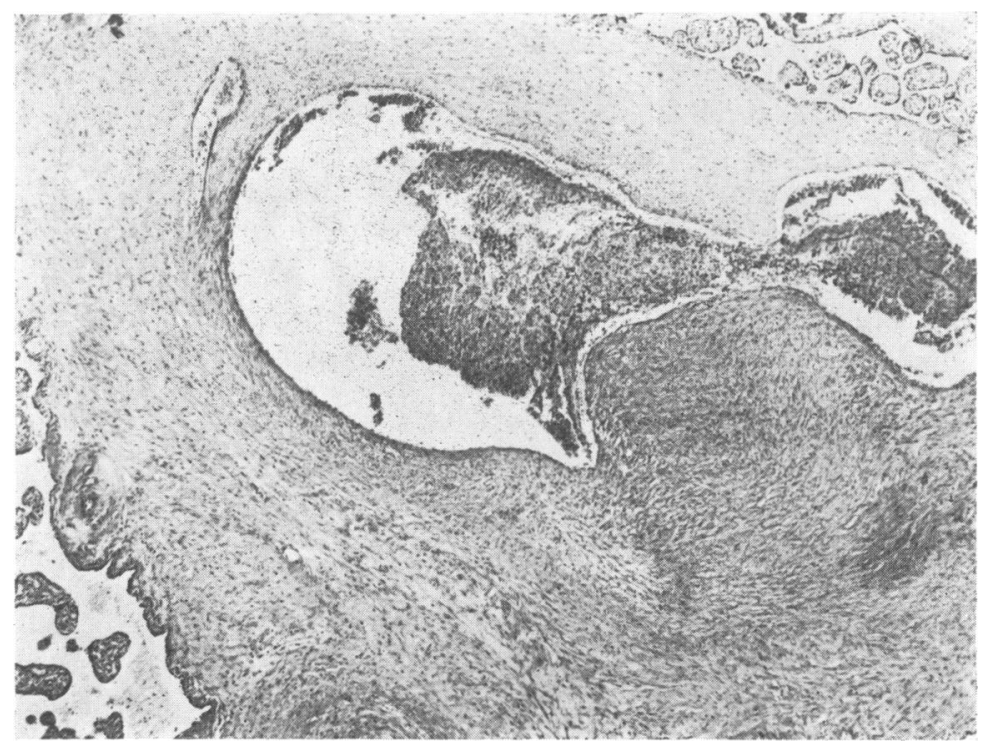

FIG. 6.-Truncal vein with protruding major intimal cushion (Case 6). $(A B / P A S \times 36$.) 
TABLE II

Summary of Histological Findings in Placentas with Subamniotic Haematomata

\begin{tabular}{|c|c|c|c|c|c|}
\hline \multirow{2}{*}{$\begin{array}{l}\text { Case } \\
\text { No. }\end{array}$} & \multicolumn{3}{|c|}{ Fetal Veins } & \multirow{2}{*}{$\begin{array}{c}\text { Fetal } \\
\text { Arteries }\end{array}$} & \multirow{2}{*}{$\begin{array}{l}\text { Villous } \\
\text { Vessels }\end{array}$} \\
\hline & $\begin{array}{c}\text { Major } \\
\text { Cushions }\end{array}$ & $\begin{array}{c}\text { Other Organizing } \\
\text { Thrombi }\end{array}$ & $\begin{array}{c}\text { Free } \\
\text { Thromboemboli }\end{array}$ & & \\
\hline $\begin{array}{l}1 \\
2 \\
3 \\
4 \\
5 \\
6\end{array}$ & $\begin{array}{l}\text { In surface and truncal veins } \\
\text { In surface and truncal veins } \\
\text { In surface and truncal veins } \\
\text { In surface and truncal veins } \\
\text { In surface and truncal veins } \\
\text { In surface and truncal veins }\end{array}$ & $\begin{array}{l}\text { Present; truncal veins } \\
\text { Present; truncal veins } \\
\text { Present; truncal veins }\end{array}$ & $\begin{array}{l}\text { Present } \\
\text { Present } \\
- \\
\text { Present } \\
-\end{array}$ & $\begin{array}{l}\text { No abnormality } \\
\text { No abnormality } \\
\text { No abnormality } \\
\text { No abnormality } \\
\text { No abnormality } \\
\text { No abnormality }\end{array}$ & $\begin{array}{l}\text { No abnormality } \\
\text { No abnormality } \\
\text { No abnormality } \\
\text { No abnormality } \\
\text { No abnormality } \\
\text { No abnormality }\end{array}$ \\
\hline
\end{tabular}

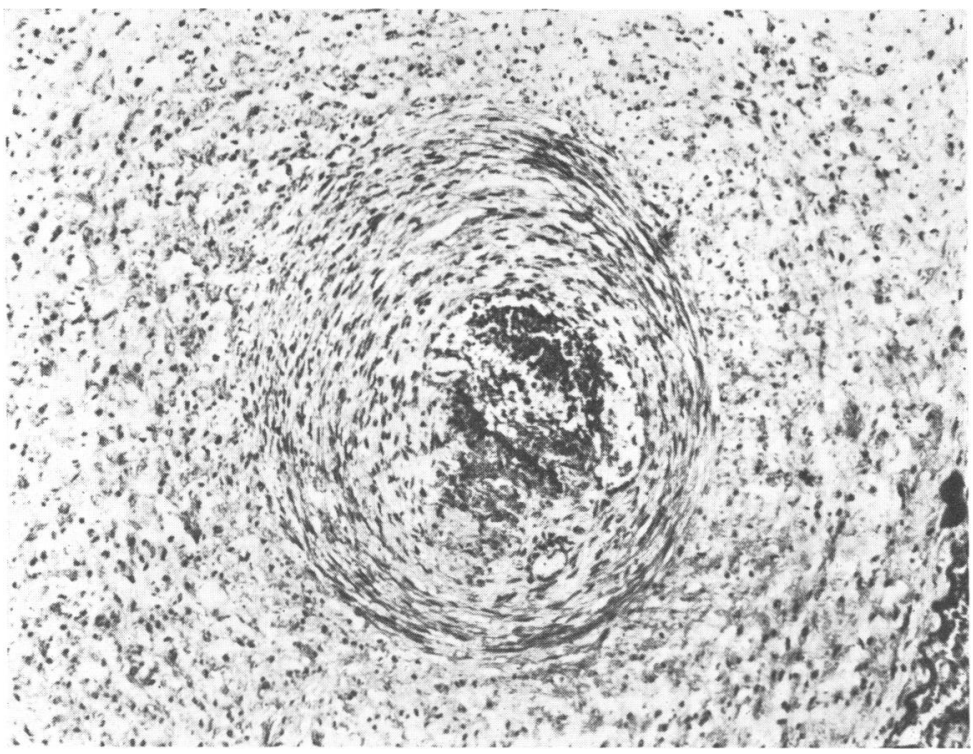

FIG. 7.-Organizing thrombus in truncal vessel (Case 5). $(M S B \times 90$.

cushions in their surface veins, but there were certain important quantitative differences. The cushions were considerably smaller, and were of the same thickness as the remainder of the vessel wall (Fig. 9), evidence of surface fibrin was only very occasionally seen, and the cushions did not show the presence of fibrin in deeper layers. Not surprisingly these cushions contained far less acid mucopolysaccharide than their counterparts in the 6 subamniotic haematoma cases. Placentae with cushions that show the characteristics outlined above will be referred to as placentae with minor cushions.

No difficulty was experienced in distinguishing between the placentae on the basis of the nature of their cushions, since they fell into two clearly different categories. Placentae were considered to have significant numbers of major cushions if more than half the surface veins showed the presence of such cushions. Doubtful or borderline cases were not encountered in the present series.

Since low birthweight score appeared to be a prominent feature of the subamniotic haematoma cases, and since many of the 'at-risk' infants had a low birthweight score, it was decided to compare the frequency of placentae with major cushions with low birthweight score in all 3 groups of cases studied. The results are shown in Table III where it can be seen that in the 'at-risk' group all 8 placentae with major cushions came from a subgroup of 21 infants with low birthweight score.

\section{Discussion}

Subamniotic haematomata have been seen in 


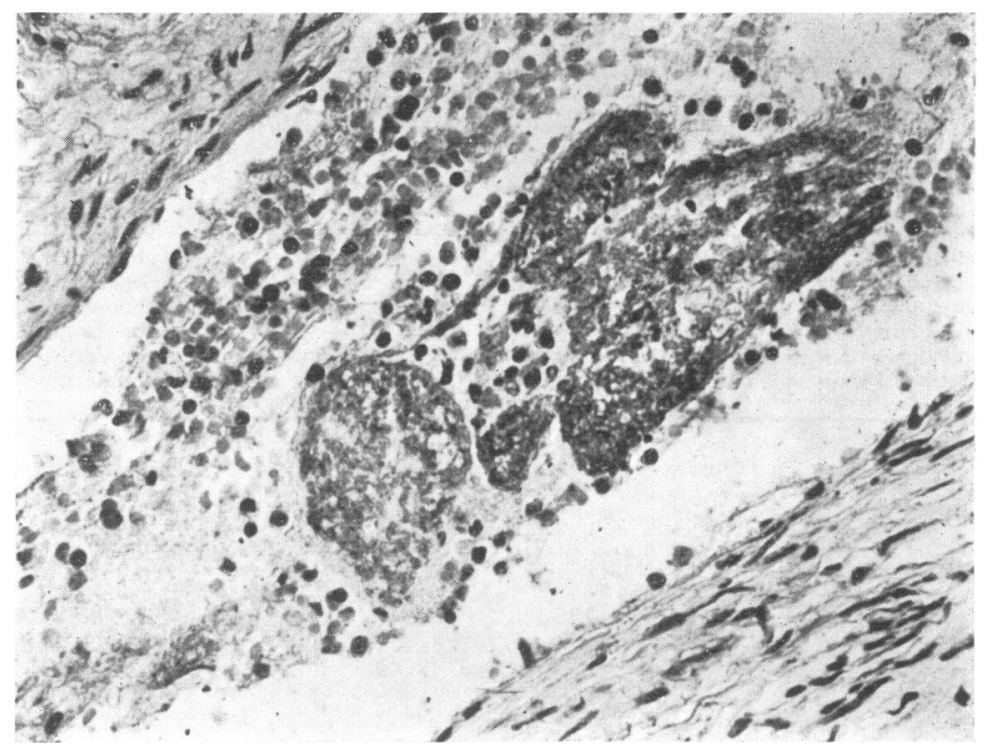

Fig. 8.-Free thrombus in truncal vein (Case 2). (MSB $\times$ 90.)

cases where the early clamping of the cord or excessive cord traction tears surface chorionic veins (P. M. Dunn, 1971, personal communication). Under these conditions, as shown by Dunn (1966), the umbilical venous pressure may rise to remarkably high levels (sometimes exceeding $150 \mathrm{mmHg}$ ). The lesions described in the present report are probably very different from these 'simple' tears since the changes in the vessel wall in the region of the rupture indicate that it has been weakened by previous rise(s) in pressure for some time. Furthermore, in the present series of cases, the haematomata have been associated with chronic lesions of the underlying surface veins. It is a pity that more cases of apparently simple tearing of surface veins have not been examined in greater detail, for it would

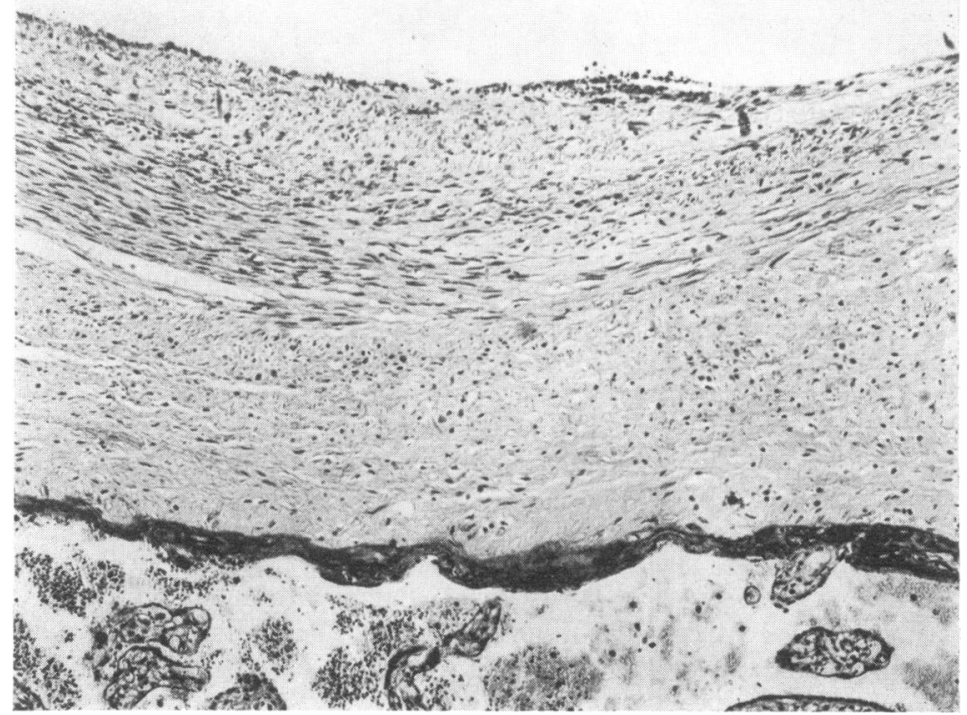

FIG. 9.-Minor cushion in varix from a normal placenta showing a trace of surface fibrin. $(M S B \times 90)$. 
TABLE III

Low Birthweight Score and Frequency of Major Endothelial Cushions

\begin{tabular}{l|r|c|c}
\hline \multicolumn{1}{c|}{ Type of Case } & No. & Low Score & Major Cushions \\
\hline SAH & 6 & 4 & 6 \\
Normal & 100 & - & 2 \\
At-risk & 35 & 21 & $8^{\star}$ \\
\hline
\end{tabular}

$\star$ All infants with low birthweight scores.

be of obvious interest to know whether these are normal umbilical veins that have ruptured and what pressures are necessary to bring about such a result.

As shown in Table I the outcome of the pregnancy cannot be attributed solely to the blood lost in the haematoma. It is possible that blood loss may have played a contributory role, but even this is uncertain since the details of the time at which the cord was clamped are unknown.

The development of major cushions is of greater interest and much more difficult to explain. Their structure indicates that they develop from organizing thrombi, but the stimulus for the initiation of such intravascular coagulation is uncertain. It is known that with increasing gestation the umbilical venous pressure rises to the high level of approximately $15 \mathrm{mmHg}$ at term (Dawes, 1968), and that the structure of the umbilical vein reflects its adaptation to this (Boyd and Hamilton, 1970).

Large intimal cushions in veins are usually seen when these vessels have been subjected to increased pressure, and varicose veins, haemorrhoidal veins, and the veins in arteriovenous aneurysms are wellknown examples of this phenomenon. It is very likely then that the major cushions seen in this series represent vascular damage due to raised pressures in the umbilical vein. Since all the umbilical vessels are known to be capable of profound vasoconstriction in response to hypoxia and/or catecholamine release (Dawes, Mott, and Rennick, 1956), spasm of vessels may also play a part in producing the lesions seen. Recently (Sanerkin, 1971) it has been shown that variations in the duration of vascular spasm can modify and alter the pattern of vascular lesions produced by rapid rises in blood pressure.

Organizing thrombi have been described in the chorionic circulation in the placentae of dysmature infants previously (Gruenwald, 1963), but they do occur in other infants as well, notably the infants of diabetic mothers (Benirschke and Driscoll, 1967). It appears likely that these lesions are the result of some fetal mechanism that may be brought into play in response to a wide range of stresses. Whatever their pathogenesis the lesions described in this paper and by previous workers occur in the fetal circulation, and that they seem to be commoner in infants of low birthweight score is of considerable interest since they may provide a clue to the pathophysiology of such infants.

I would like to acknowledge the help of the staff of the Nuffield Maternity Home and Department of Obstetrics and Gynaecology, Churchill Hospital, Oxford, for their help in analysing the clinical data presented.

\section{REFERENCES}

Benirschke, K., and Driscoll, S. G. (1967). The Pathology of the Human Placenta, p. 312. Springer, New York.

Boyd, J. D., and Hamilton, W. J. (1970). The Human Placenta, p. 207. Heffer, Cambridge.

Dawes, G. S. (1968). Foetal and Neonatal Physiology, p. 66. Year Book Medical Publishers, Chicago.

Dawes, G. S., Mott, J. C., and Rennick, B. R. (1956). Some effects of adrenaline, noradrenaline and acetylcholine on the foetal circulation in the lamb. Fournal of Physiology, 134, 139.

Dunn, P. M. (1966). The placental venous pressure during and after the third stage of labour following early cord ligation. fournal of Obstetrics and Gynaecology of the British Commonwealth, 73, 747.

Dunnill, M. S. (1968). Quantitative methods in histology. In Recent Advances in Clinical Pathology, Series V, p. 401. Ed. by S. C. Dyke. Churchill, London.

Gruenwald, P. (1963). Chronic fetal distress and placental insufficiency. Biologia Neonatorum, 5, 215.

Gruenwald, P. (1969). Growth and maturation of the foetus and its relationship to perinatal mortality. In Perinatal Problems; The Second Report of the 1958 British Perinatal Mortality Survey. Ed. by N. R. Butler and E. D. Alberman. Livingstone, Edinburgh.

Sanerkin, N. G. (1971). Vascular lesions of malignant essential hypertension. Fournal of Pathology. (In the press.)

Correspondence to Dr. D. J. deSa, Harkness Laboratory, Department of Pathology, Radcliffe Infirmary, Oxford. 